\title{
A vibração e o silêncio em "Canção", de Fernando Pessoa
}

\author{
Carlos Rogério Duarte Barreiros ${ }^{1}$
}

\section{Resumo}

Por meio da análise do poema "Canção", de Fernando Pessoa, são identificadas as características do Estilo Lírico proposto na obra Conceitos fundamentais da poética, de Emil Staiger, especialmente a integração de sujeito e objeto, ou o um-no-outro lírico. Essa investigação, por sua vez, permite a sugestão de que o poema analisado contém em si, de modo singularmente sintético, algumas das características nucleares da obra do poeta português.

Palavras-chave: Fernando Pessoa; canção; lírica

\begin{abstract}
Through the analysis of the poem "Canção" by Fernando Pessoa, one can identify some characteristics of the "Lyrical Style" proposed in Emil Staiger's Conceitos fundamentais da poética, especially the integration of subject and object, or the "one-in the-other" lyric. This article, in turn, allows the suggestion that the poem analyzed contains in itself, in a singularly synthetic way, some of the nuclear features found in the work of the Portuguese poet.
\end{abstract}

Keywords: Fernando Pessoa; "Canção"; lyrical

\section{Investigação da canção}

Para engendrar a análise de "Canção", de Fernando Pessoa, talvez não seja vão começar pelo título do poema. Segundo o Dicionário das literaturas portuguesa, brasileira e galega (COELHO), a canção é "Poema de fundo lírico e geralmente de forma culta", embora haja canções também de origem popular. Trata-se de forma poemática de difícil classificação, porque a "designação abrange pelo menos três gêneros literários, talvez relacionados entre si, mas afinal muito diferentes: a canção provençal, a canção italiana ou clássica, e a canção romântica" (Idem). Não há, em todo o verbete, classificação objetiva, em termos formais ou temáticos, em que se possa incluir a canção pessoana que será analisada neste texto. Aliás, é relevante perceber que uma pesquisa rápida em bibliografia de referência leva a apenas uma conclusão a respeito da canção: talvez ela seja - ressalvada sua forma rigorosamente erudita, cultivada em língua portuguesa por Camões - o poema inclassificável por natureza.

A pesquisa na obra de Massaud Moisés (1984) leva, necessariamente, a uma fonte mais esclarecedora do que todas as obras de referência: os Conceitos Fundamentais da Poética, de Emil Staiger (1972), cujo capítulo intitulado "Estilo Lírico: A Recordação” servirá de referência para a conceituação da canção.

Primeiramente, em termos gerais, a canção é a forma poemática lírica por excelência. Para Staiger (Ibid, p.15), “Ao falar de 'clima lírico' ('lyrische Stimmung’)

\footnotetext{
${ }^{1}$ Doutorando do Departamento de Letras Clássicas e Vernáculas (DLCV) da Faculdade de Filosofia, Letras e Ciências Humanas (FFLCH) da Universidade de São Paulo (USP).
} 
ou de 'tom lírico', ninguém está pensando em um epigrama; mas qualquer pessoa pensa imediatamente em uma canção (Lied)". Essa correspondência entre lírica e canção se dá por diversos motivos, cuja análise pormenorizada levaria este texto muito além dos limites a que o autor se propõe. Sumariemo-los, pois, rapidamente.

Primeiramente, não será surpreendente para o leitor a afirmação de que tanto a lírica em geral quanto a canção em particular guardam ancestralidade em composições híbridas, compostas por dois elementos: a letra - designação recente para o texto em versos - e a melodia, por meio da qual a letra é entoada, com maior ou menor acompanhamento de instrumentos, conforme a época (tradição que se perpetua na canção popular, nos termos propostos na pesquisa de Luiz Tatit ${ }^{2}$ ). O elemento mais marcante do gênero lírico e, consequentemente, de sua forma expressiva mais típica, a canção, já desligada do acompanhamento musical, é o que poderíamos chamar de indiferenciação da forma e do conteúdo, ou ainda, se quiséssemos, de unidade entre a significação das palavras e sua musicalidade, numa integração que singulariza o gênero lírico (STAIGER, 1972, p.26): "Na criação lírica, (...) metro, rima e ritmo surgem em uníssono com as frases. Não se distinguem entre si, e assim não existe forma aqui e conteúdo ali”. Mais do que isso: o autor põe em xeque, por meio dessa afirmação, os conceitos de subjetividade e objetividade, sugerindo que o que caracteriza o estilo lírico é a integração de sujeito e objeto, o que chama de um-no-outro lírico. Definição cujo debate, repita-se, vai além dos limites deste texto, mas extremamente fértil para esta análise, como se observará a seguir.

Sempre com base em poemas, compostos principalmente em língua grega ou alemã, Steiger propõe detalhadamente os conceitos expostos acima e expõe características gerais do que chama de estilo lírico, sempre com a ressalva de que, em última análise, cada poema terá seu tom, na exata medida em que é expressão de sujeitos em situações efêmeras, registradas ao sabor da "disposição anímica", em que o sujeito poético se vê tomado por algo que está diante dele. Essas características, de forma geral, são as seguintes: abundância de recursos sonoros, à beira da

\footnotetext{
${ }^{2}$ Embora os textos de Luiz Tatit não sejam citados ao longo do artigo, nem na bibliografia, o contato com a obra desse autor foi extremamente útil e esclarecedor na leitura do primeiro capítulo dos Conceitos fundamentais da poética, especialmente no fragmento a respeito dos tons assumidos por cada "mestre do melo" (Staiger, 1972, p.26) e no trecho de conceituação de "disposição anímica" (Ibid, p. 59), extremamente similar ao conceito de conjunção entre sujeito e objeto na semiótica greimasiana, ponto de partida de Tatit para formular a análise da canção popular. Fica em aberto o desafio de investigar pontos de contato entre a forma poemática da canção e a canção popular do século XX.
} 
dessemantização das palavras, expressão última da ancestralidade na combinação texto e melodia; concisão da composição, na medida em que esta é expressão do momento fugaz de integração do sujeito e do objeto; recorrência de elementos repetitivos, como refrãos, que garantem, no texto, a "volta ao momento da inspiração lírica" (STAIGER, 1972, p.35); e, finalmente, predominância do tempo presente, em que está sintetizada a análise de Staiger, no fragmento a seguir:

O conceito "presente" deve ser tomado ao pé da letra. Deve indicar um frente-a-frente. (...) $\mathrm{O}$ poeta lírico nem torna presente algo passado, nem também o que acontece agora. Ambos estão igualmente próximos dele; mais próximos que qualquer presente. Ele se dilui aí, quer dizer ele "recorda". "Recordar" deve ser o termo para a falta de distância entre sujeito e objeto, para o um-no-outro lírico. (Ibid, p.59)

\section{Erupção e vibração, em linhas sílficas e gnômicas}

Todas as observações anteriores apontam para uma única direção que deve ser seguida para dar início à análise de "Canção": suas características formais. O poema é composto de cinco quadras de versos hexassílabos. A regularidade das estrofes e da métrica dos versos é, portanto, marcante, ao contrário do que ocorre com as rimas que, embora existam, não seguem a mesma uniformidade. Com efeito, todos os versos pares rimam rigorosamente, o que não ocorre com os ímpares.

A irregularidade rímica, aliás, abre portas para avaliações mais detidas no que diz respeito à musicalidade de "Canção". De um lado, embora todos os versos tenham seis sílabas poéticas, cada um deles guarda diferentes entoações internas que vale a pena analisar; de outro, observa-se entre muitos dos versos o recurso de enjambement, que parece, em alguns momentos, garantir a fluência da leitura do poema, fazendo correr a frase onde as entoações variam.

Antes de analisar em detalhes esses recursos sonoros, convém lembrar que refrão e paralelismo são recursos bastantes presentes nas cantigas da tradição medieval e nas canções populares até hoje, embora não sejam obrigatórios nas manifestações poemáticas da canção; da mesma maneira, note-se que a palavra "estrofe" vem do vocábulo grego strophê, que expressa a "ação de voltar" (MoIsés, 1984, p. 230). Finalmente, já vimos que, para Steiger, reiterações sugerem, nos textos líricos, o retorno ao momento da inspiração. Com essas informações, não será precipitado supor que, principalmente na canção, associada que está à música, é recorrente o movimento de ida-e-volta - que também pode ser observado, por exemplo, em redondilhas medievais 
que contêm um mote a ser glosado. Em "Canção", ainda que não haja, a rigor, nem refrão, nem estruturas frasais flagrantemente paralelísticas, nem mote a glosar, a estrutura sonora guarda repetições, como se o texto contivesse, em miniatura ou embrião, mais recorrências e voltas melódicas do que se pode notar em uma leitura desatenta.

O primeiro verso já apresenta estrutura de interesse. "Silfos ou gnomos tocam?..." chama a atenção, primordialmente, por dois motivos: a quarta sílaba do verso, "gno", tônica, contém um encontro consonantal bastante singular em língua portuguesa, que naturalmente trava a leitura, o que também ocorre com a interrupção imposta pelo ponto de interrogação seguido de reticências. De forma geral, a impressão que fica, do ponto de vista fônico, é a de que o andamento do verso está travado; semanticamente, ocorre o mesmo: a dúvida deixa em suspenso a leitura, o que está asseverado por meio das reticências.

Silfos ou gnomos tocam?...

Roçam nos pinheirais

Sombras e bafos leves

De ritmos musicais.

Mas esse travamento é subvertido a seguir, porque a sequência de sibilantes ainda timidamente ensaiada, mas já previamente anunciada nas desinências nominais de plural do primeiro verso -, o recurso do enjambement e a rima dão fluência aos três versos seguintes. Note-se que outro encontro consonantal incomum, em "ritmos", no quarto verso, não tem a mesma força observada em "gnomos", do primeiro, em que a anomalia se dava nos dois primeiros fonemas da palavra, o que impede o leitor de separar as consoantes em duas sílabas. Em "ritmos", /t/ fica numa sílaba, /m/ na outra. Assim, mesmo a ocorrência de um encontro consonantal não interrompe o correr dos vocábulos e a musicalidade dos versos.

Relacionemos esses aspectos meramente fônicos a outros, de ordem lexical, sintática e semântica. No primeiro verso, chama a atenção, primeiramente, a escolha dos vocábulos "silfos" e "gnomos". Silfos são, na mitologia céltica e germânica, seres sobrenaturais, de graça delicada, dotados de asas, compostos dos elementos mais puros do ar, onde vivem; gnomos também são seres sobrenaturais, mas caracterizam-se pelos traços fisionômicos feios, além de habitarem a terra, em que guardam pedras e metais preciosos. Do ponto de vista etimológico, de um lado, "silfo" é palavra de origem 
incerta, mais provavelmente do francês; de outro, as raízes de "gnomo" são bem menos obscuras: o vocábulo teria vindo do grego genomus, que significa "habitante da terra", ou gnóme, - es, “julgamento, bom senso, reflexão".

Todos os elementos acima parecem apontar para a oposição entre silfos e gnomos: embora ambos sejam seres da ordem do maravilhoso, os primeiros parecem remeter mais diretamente à subjetividade, pela singeleza, pela origem aérea, pelo voo, pelo mistério na origem do vocábulo; os gnomos, por sua vez, estão diretamente associados ao universo material e concreto, pela fealdade, pela origem terrena e pela racionalidade indicada na etimologia. Estão estabelecidas, pois, na canção, as duas linhas de força que se alternam: a primeira, silfica, subjetiva, etérea, dinâmica, que faz correr vento (no plano da imagem construída na primeira estrofe) e fonemas (no plano sonoro dos versos em enjambement: são as "Sombras e bafos leves / De ritmos musicais"), linha que predomina nas duas primeiras estrofes; a segunda, gnômica, objetiva, racional, telúrica, estática, ganha força a partir da terceira estrofe e é desenhada por meio da imagem dos pinheirais plantados na terra.

Desse modo, fica evidente que o travamento, no plano fônico, do primeiro verso coincide com o encontro entre as duas linhas de força que se opõem na canção, como se estivessem em atrito, mas não em conflito: estão combinadas. É a erupção de todo início de canção. Se quiséssemos falar com Staiger (Idem, p.28), diríamos que, na primeira estrofe, estamos diante do momento do abandono do sujeito poético à inspiração: "Ele inspira ao mesmo tempo clima e linguagem. (...) Seu poetar é involuntário. Os lábios deixam escapar o "que está na ponta da língua”". Fascina o sujeito poético a vibração do vento nas folhas de pinheirais, das forças sílficas nas gnômicas. Em "Silfos ou gnomos tocam?", a forma verbal destacada, além de sugerir o irromper da música, isto é, do vento soando nas folhas, aponta para o tempo verbal mais recorrente na lírica: o presente, por meio do qual as melodias são retomadas e atualizadas no momento mesmo da leitura - reforçando-lhes, também, a fugacidade, já que elas serão atenuadas ao longo do poema até desaparecerem por completo na última estrofe. O atrito que, no plano fônico, se observa por meio do encontro consonantal em "gnomo", depois se estabiliza (poder-se-ia dizer silficamente) por meio das sibilantes, do enjambement e da rima, como se presenciássemos os primeiros acordes ou as primeiras entoações de uma canção; na mesma medida, no plano do conteúdo, a imagem dos primeiros versos 
espelha a coincidência entre sujeito e objeto. Trata-se do registro da "disposição anímica" (Ibid., p.59), estado em que o sujeito se vê tomado "por algo que espacial e temporalmente - como essência corpórea - acha-se em frente a ele", espécie de continuum que dá origem à poesia lírica.

Resta observar que a fluência dos três últimos versos da primeira estrofe parece indicar a congruência do movimento aéreo dos silfos com a imobilidade gnômica dos pinheirais, já que a melodia só se dá por meio do roçar do vento nas folhas dessas árvores. $\mathrm{Ou}$, em palavras mais simples: no breve instante expresso em versos pelo sujeito poético, as forças sílficas e gnômicas produzem a singeleza do equilíbrio, da harmonia, após um breve reencontro inicial. Observe-se, finalmente, que a coincidência entre "pinheirais" e "musicais" ocorre não só no plano fônico, mas também no semântico, num contexto em que tudo é integração.

A segunda estrofe parece ser, inicialmente, continuação ou suspensão desse momento único: o recurso do enjambement confere unidade aos quatro versos.

Ondulam como em voltas

De estradas não sei onde

Ou como alguém que entre árvores

Ora se mostra ou esconde.

Ficou para trás, propositalmente, um dado fundamental da primeira estrofe: a sinestesia flagrante da expressão "sombras e bafos leves de ritmos musicais", sujeito semântico da forma verbal "ondulam", da segunda. Note-se que o elemento visual "sombras" e o táctil-olfativo "bafos", associados ao mais importante, o auditivo, servem, de um lado, para presentificar a imagem construída e, de outro, para carregarlhe as tintas, quase literalmente. Lembremo-nos de que essas sombras e hálitos sonoros estão ligados aos silfos, seres que vivem no ar - ou seja, em todos os lugares, inclusive no próprio sujeito. A sinestesia contribui, pois, para fazer notar que as forças sílficas estão por toda a parte, seja no plano fônico ou na própria imagem construída nos versos, o que se acentua com a recorrência de verbos no presente do indicativo e que assevera a coincidência entre sujeito e objeto: o eu poético está eivado do encontro de forças sílficas e gnômicas.

Essa hipótese se confirma na segunda estrofe, em que as sombras e bafos de ritmos musicais "ondulam como em voltas / de estradas não sei onde". Primeiramente, 
observemos que a ondulação é característica marcante do som, definido fisicamente como vibração:

Sabemos que o som é onda, que os corpos vibram, que essa vibração se transmite para a atmosfera sob a forma de uma propagação ondulatória, que o nosso ouvido é capaz de captá-la e que o cérebro a interpreta, dando-lhe configurações e sentidos. (WISNIK, 1989, p.17)

O trecho final das observações de José Miguel Wisnik será de grande utilidade mais adiante. Por ora, basta perceber que, devido à vibração, que abre a segunda estrofe com a forma verbal "ondulam", estamos, de fato, em pleno flagra sonoro aberto na imagem da primeira. Além disso, é notável que as sombras e bafos ondulem em voltas, pois já vimos que a palavra "estrofe" vem do grego strophê, que significa "ação de voltar". Trata-se de tentativa de suspender, por meio da reiteração, a imagem iniciada na primeira estrofe. Tentativa ainda sustentável na segunda, mas inviável nas seguintes, como observaremos, seja pela fugacidade dos elementos sílficos, seja pela impossibilidade de reter longamente, no poema, a impressão que eles causam: "Toda composição lírica autêntica deve ser de pequeno tamanho" (STAiger, 1972, p.28).

As ondulações do início da segunda estrofe parecem remeter, também, à tessitura musical, isto é, à variação ou amplitude dos extremos do grave ao agudo. A imagem poética refere-se à ondulação, em que, obviamente, quando se alcança o ponto mais agudo, só se pode retornar ao mais grave - e assim sucessivamente, daí à ideia das voltas e da repetição, na segunda estrofe, da imagem construída na primeira, agora com uma pequena diferença: o sujeito poético flagrou, nesta, o momento em que irromperam as sombras e bafos leves de ritmos musicais, mas não sabe, naquela, aonde eles o levam, eivado que está da força sílfica onipresente. Não será equivocado concluir que advém dessa contaminação certo caráter metalinguístico do poema: tomado dos percursos melódicos da harmonia entre forças sílficas e gnômicas, o eu se vê obrigado a tentar descrever-lhe as ondulações. Nos termos de Staiger (Ibid, p.29) "o poeta é arrastado nos altos e baixos da corrente anímica e seus versos acompanham, linograficamente, essas mudanças". Trata-se, evidentemente, da indiferenciação entre sujeito e objeto: aquele, sensibilizado por este, transforma-o em parte de si por meio da escrita da canção, em que se fundem num só. As sombras e bafos leves de ritmos musicais também ondulam "como alguém que entre árvores / Ora se mostra ou esconde" - imagem que parece repetir aquela que já foi interpretada anteriormente: o ora mostrar-se, ora esconder-se, 
retoma a ideia da oscilação; o fato de ela dar-se entre árvores recupera a combinação silfos-gnomos.

\section{Dissipação e extravio}

A metalinguagem guarda a senha para compreensão da terceira estrofe. No universo musical, a tessitura vai do grave ao agudo, rumando de volta ao grave; nas canções populares atuais e cantigas medievais, estrofes podem ser entendidas como percursos poéticos de distanciamento seguido de volta ao refrão; na "Canção" de Pessoa, não poderia ser diferente: depois das duas primeiras estrofes, é iminente o retorno ao estado anterior à combinação das forças sílficas e gnômicas - o silêncio, a ausência de vibração, a permanência destas forças em detrimento da fugacidade daquelas.

Com efeito, por mais paradoxal que pareça, o silêncio é parte do som, na medida em que é sua contraparte:

pode-se dizer que a onda sonora é formada de um sinal que se apresenta e de uma ausência que pontua desde dentro, ou desde sempre, a apresentação do sinal. (O tímpano auditivo registra essa oscilação como uma série de compressões e descompressões.) Sem este lapso, o som não pode durar, nem sequer começar. Não há som sem pausa. O tímpano auditivo entraria em espasmo. O som é presença e ausência, e está, por menos que isso pareça, permeado de silêncio. (WISNIK, 1989,p.18)

Se no universo da música e da canção, tudo é volta; se uma nota musical só compõe sentido porque se opõe à anterior; se um fonema só está investido de significado na medida em que se opõe a outro, então não parece ilógico ou anormal que o silêncio seja parte do som, ou, se quisermos, com Wisnik, "o som está permeado de silêncio". É o que começa a se anunciar na terceira estrofe:

Forma longínqua e incerta

Do que eu nunca terei...

Mal oiço, e quase choro.

Por que choro não sei.

Do ponto de vista formal, interrompeu-se o enjambement, com quebras da fluência do texto: as reticências lembram as hesitações do primeiro verso do poema; a vírgula e o ponto-final truncam a leitura. Esse desmantelamento fônico tem correlações no plano semântico. Nos dois primeiros versos da terceira estrofe, as "sombras e bafos 
leves de ritmos musicais" soando nos pinheirais são a "forma longínqua e incerta" daquilo que o sujeito jamais terá. Está iniciada a dissipação da imagem espetacular flagrada na primeira estrofe e estendida ao longo da segunda. A partir de então, as forças sílficas perderão força paulatinamente, como se a vibração musical se atenuasse, à medida que ganha espaço a "música dos pinheirais".

Com efeito, o sujeito pouco ouve, porque estão se esvaindo as vibrações sílficas nas árvores, e quase chora, sem saber por quê. Os versos soam como lamento: o desaparecimento gradual das melodias naturais pode ser entendido, a um só tempo, como extravio da integração entre sujeito o objeto. Em palavras mais simples, é por meio do desfrute da experiência natural que o sujeito experimenta a integração com ela e consigo próprio. Perdê-la é também perder-se, daí o choro injustificado.

Note-se ainda que a categoria do saber ("Por que choro não seil") está alinhada à ordem gnômica: parece que entra em cena "o sujeito cerebral" pessoano, que se vê, aqui, acuado pela perda das melodias subjetivas, intangíveis e onipresentes a que está submetido, de modo que não lhe resta alternativa a não ser tentar traduzi-las em verso. Talvez seja esta a origem da escrita de "Canção": o intento de reter em versos a erupção, a vibração mais elevada e a dissolução de um momento tão fugaz quanto a viração das folhas. Momento precioso, sem dúvida, na medida em que proporciona ao sujeito poético a experiência rara de integração com o objeto e consigo próprio - de certa forma, síntese da busca engendrada por Pessoa em sua obra.

Tão tênue melodia

Que mal sei se ela existe

Ou se é só o crepúsculo,

Os pinhais e eu estar triste.

É fato: as sombras e bafos leves de ritmos musicais estão se perdendo, sua vibração parece reduzir-se, são melodias agora frágeis, sutis, que se atenuam, a ponto de sua existência estar posta em xeque. A linha tênue que parece confirmar-lhes a presença é, ainda mais uma vez, o recurso do enjambement. A essas impressões sonoras associase o ocaso, sombreando a imagem, em que só restam os pinhais - elemento gnômico - e o sujeito poético, ainda tomado dos ecos melódicos que o sensibilizaram, mas já triste, em coincidência com a imagem crepuscular. Está rasurada a harmonia entre silfos e gnomos, porque começam a prevalecer estes sobre aqueles, que agora saem de cena para dar lugar ao fim do dia. As impressões auditivas - rigorosamente da ordem sílfica e 
subjetiva, afinal "Sobre a música são válidas as palavras de Paul Valéry que dizem: a música suprime o espaço. Estamos nela e ela em nós" (STAIGER, 1972, p. 52) - dão lugar às visuais - do plano gnômico e objetivo. A integração perder-se-á em dispersão, nas trevas do fim do dia, e em anulação do som, o silêncio gnômico que encerrará o poema.

A interpretação não é simples: o sujeito poético começa a se ver, agora, abandonado da música que o encantara, e imerso na escuridão, habitada apenas do elemento telúrico, os pinhais. Ganha prevalência, aqui, o espaço da razão, pelo qual se encerra a análise.

\section{A música dos pinheirais: razão poética de Fernando Pessoa}

O percurso adotado anteriormente leva à conclusão de que o que resta, sem a presença dos silfos, é o silêncio absoluto, mas a última estrofe parece não permitir essa conclusão.

Mas cessa, como uma brisa

Esquece a forma aos seus ais;

E agora não há mais música

Do que a dos pinheirais.

A melodia em que se combinavam silfos e gnomos desaparece finalmente, comparada a uma brisa que "esquece a forma aos seus ais". Não há mais o roçar dos ventos nas folhas dos pinheirais, ou seja, desapareceu a vibração sílfica no poema. Já sinalizamos também que o elemento fundamental da lírica e, por consequência, da canção - a integração entre sujeito e objeto - parece comprometido nos versos pessoanos. Observamos, entretanto, ao longo das cinco estrofes, o árduo empreendimento poético do sujeito: motivado e tomado das melodias emitidas pelo correr do vento nas folhas, ele pretendia criar uma canção que retivesse a experiência rigorosamente lírica, na exata medida em que se viu confundido com aquilo que representava e com a representação em $s i$ - o próprio poema. Tentativa, em alguma medida, lograda e malograda: o domínio técnico da forma implica, em alguma medida, organizá-lo de forma coerente, para que não se perca, como as forças sílficas, ao vento. É inevitável, pois, que o que ocorra, ao final, seja o distanciamento do universo sílfico. No mais, tudo que é musical implica retorno: o silêncio é parte do som, como já vimos. Finalmente, Staiger (1972, p. 29) perguntava "quando o poeta é arrastado nos altos e baixos da corrente anímica e seus versos acompanham, linograficamente, essas 
mudanças, onde fica a unidade de que necessita sua obra de arte?’. A unidade estará, evidentemente, nas recorrências formais do poema - formuladas racionalmente, com ancestralidade (raízes gnômicas, se quisermos) nas voltas tradicionais. Caso contrário, o mero errar ao sabor da corrente anímica levaria ao "ideal de ininterrupta existência lírica, ideal não mais possível artisticamente, e que leva à total desintegração do eu". Na lírica, se é verdade que sujeito e objeto estão confundidos, só a organização formal do poema pode resultar, em certa medida, na organização do próprio sujeito.

Os dois últimos versos são, portanto, esclarecedores: nada mais resta a não ser a música dos pinheirais, que exige interpretação. Se as árvores de "Canção" remetem aos gnomos, ao universo telúrico e material, à categoria do cogito, em oposição à brisa e à subjetividade sílficas, não parece equivocada a hipótese de que a música dos pinheirais remeta diretamente à razão - e, portanto, ao domínio da técnica da escrita poética - e à permanência - no plano musical, o oposto da vibração e da ondulação, portanto, o silêncio, mas ainda investido de sentido, porque se opõe às ondulações anteriores. Não há vibração nem ondulação na música dos pinheirais, por isso a ambiência, retomando as sinestesias anteriores, perde a cor, escurece. Interrompe-se a melodia, cai o dia e "Canção" se encerra, com o vazio cheio de sentido do último verso.

Como compreender o remate do poema? Primeiramente, observemos que, num primeiro plano, mais superficial, mas não menos complexo, pode-se entender a canção acima como metalinguística. Com efeito, na primeira e na segunda estrofes, o que se pode observar é a gênese do poema: o correr da brisa nas árvores toca a sensibilidade do $e u$, que tenta exprimir-lhe os sentidos melódicos em versos. Tendo percebido, já na terceira, que lhe era impossível apreendê-los continuamente, na medida em que estavam carregados de conteúdo fugaz, o eu lamenta que este lhe escape - e este lamento é mesmo o poema que temos diante dos olhos, mas ainda erigido sobre as raízes gnômicas, da ordem da razão.

Paralelamente à metalinguagem, mas num plano menos aparente, concorrem no poema as forças a que chamamos sílficas e gnômicas. Estas foram entendidas como a organização racional que sujeito poético imprime a todo o texto, ordenando-o em cinco estrofes de versos hexassílabos, dialogando (apesar da dificuldade de definição observada no início desta análise), em certa medida, com a tradição literária da canção em língua portuguesa: basta a regularidade formal do poema, o movimento de ida-e- 
volta, para que ele seja associado a um modelo anterior, ainda que esse modelo tenha ganhando diversas formas ao longo do tempo. Notemos que tradição é uma forma de permanência, o que reforça a imagem concreta e telúrica dos pinheirais, que podem ser entendidos como a forma poemática da canção, enraizada na tradição, cujas técnicas o sujeito poético domina. $\mathrm{Na}$ outra ponta, os influxos sílficos foram interpretados como o conteúdo efêmero da imagem que toma de assalto o sujeito. Está no ar - por isso é sílfico, etéreo, ubíquo -, no sujeito e fora dele, o conteúdo da canção, subjetivo e objetivo a um só tempo, momentaneamente perceptível pela sensibilidade do sujeito.

Para Staiger,

Se queremos encontrar a nós mesmos, não podemos descer ao nosso íntimo; temos que ser buscados fora, sim, fora de nós. Como arco-íris fantástico nossa alma ameaça-se sobre a precipitação irresistível da existência. Não possuímos nossa pessoa; ela nos sopra de fora, fogenos por muito tempo e volta-nos num sopro. Apesar de ser nossa "pessoa". (Staiger, 1972, p.60)

Parece-nos inevitável, frente à leitura do fragmento acima, a imagem de que a mínima parte de um todo pode também contê-lo integralmente, por mais paradoxal que pareça. Com efeito, a "Canção" de Fernando Pessoa é expressão da busca do sujeito poético pessoano por si mesmo, espécie de autoprecipitação, por meio do mergulho no que lhe parece alheio. Mas apenas parece alheio, na medida em que, o que nos toca à sensibilidade já é, conquanto pareça estranho, um pouco de nós. No poema analisado, soprou de fora a pessoa do sujeito poético (pessoano), fazendo que ele experimentasse, num átimo de duas estrofes, a integração essencialmente lírica entre sujeito e objeto, em eflúvio, entre ele próprio e a imagem que o encantou, entre essa experiência e sua expressão - a canção.

Talvez a obra de Fernando Pessoa seja tentativa incansável de desfrutar dessa experiência - observada de modo singular no poema analisado - inúmeras vezes, por meio de diferentes eus - os heterônimos.

Lembremo-nos, finalmente, das palavras de José Miguel Wisnik: o cérebro humano interpreta a propagação ondulatória do som, "dando-lhe configurações e sentidos". Com o desaparecimento do sopro sílfico, resta a razão do sujeito poético, que cumpre a tarefa metódica a que se propôs, concluindo a "Canção". O que sente, no sujeito poético pessoano, está pensando. 


\section{Bibliografia}

COELHO, Jacinto do Prado. Dicionário das literaturas portuguesa, brasileira e galega. Porto: Livraria Figueirinhas, s.d.

MOISÉS, Massaud. A criação literária: poesia. São Paulo: Cultrix, 1984.

STAIGER, Emil. Conceitos fundamentais da poética. Trad. Celeste Aída Galeão. Rio de Janeiro: Tempo Brasileiro, 1972.

WISNIK, José Miguel. O som e o sentido: uma outra história das músicas. São Paulo: Companhia das Letras, 1989. 